\title{
Experimental Study of Vertical Axis Wind Turbine Performance under Vibration
}

\author{
Md Rasel Sarkar a,b,1, ${ }^{*}$, Sabariah Julai b,2, Mst Jesmin Nahar c,3, Moslem Uddin d,4,*, \\ Mahmudur Rahman b,5, Md. Riyad Tanshena,6 \\ ${ }^{\text {a }}$ Department of Electrical and Electronic Engineering, World University of Bangladesh, Dhaka 1205, Bangladesh \\ ${ }^{\mathrm{b}}$ Department of Mechanical Engineering, University of Malaya, 50603 Kuala Lumpur, Malaysia \\ ${ }^{c}$ Department of Mathematics, Begum Rokeya University Rangpur, Rangpur 5400, Bangladesh \\ ${ }^{\mathrm{d}}$ Centre for Smart Grid Energy Research (CSMER), Universiti Teknologi PETRONAS, 32610 Perak, Malaysia \\ ${ }^{1}$ raselbdeee@gmail.com; ${ }^{2}$ sabsz@um.edu.my; ${ }^{3}$ mjnahar901@ @rur.ac.bd; ${ }^{4}$ moslem.uddin.bd@ gmail.com; \\ 2mahmud220711@gmail.com; ${ }^{6}$ riyadrt@gmail.com \\ * Corresponding Author
}

ARTICLE INFO

Article history

Received 05 May 2021

Revised 17 June 2021

Accepted 22 June 2021

Keywords

Vertical axis wind turbine;

Power generation;

Vibration;

Operating deflection shape;

Experimental modal analysis

\begin{abstract}
An experimental study was conducted to study the effects of flow uniformity on vibration and power generation of a small vertical axis wind turbine (VAWT). Previous studies have confirmed that one of the sources of vibration in the turbine is due to aerodynamic forces, which are due to incident wind. Firstly, understanding vibration is essential before proceeding to the measurements. In this experiment, further understand the vibrations of the turbine in operation, the operating deflection shape (ODS) technique was used. A wind tunnel and flow conditioner were fabricated. Experimental modal analysis (EMA) was conducted, and the dynamic characteristics are gathered. The ODS was conducted for operating the turbine at different speeds, with and without the flow conditioner. Results from EMA and ODS are correlated to explain the behavior of structures. In conclusion, the flow conditioner tested did have a big impact on the response of the structure in terms of vibration up to $30 \%$ indifference, but not so much in power generated about $2 \%$ indifference.
\end{abstract}

This is an open-access article under the CC-BY-SA license.

\section{Introduction}

Wind energy had developed in the early 1970s due to the energy crisis experienced [1, 2]. It is clean and renewable; the application of wind energy is increased massively in the last few decades. Wind energy is one of the promising renewable energy resources [3]. Wind energy has utilized thought of Horizontal Axis Wind Turbine (HAWT) and Vertical Axis Wind Turbine (VAWT). The VAWTs are widely used for they can produce small-scale wind power. The kinetic energy of wind is converted into mechanical energy by the rotational of the wind turbine rotor [4].

The VAWT can dominate wind-energy technology within the next 2-3 decades. It can produce low power, which uses in urban areas where low average wind speed. The main advantages of VAWT are that it can accept any direction of wind speed and easy mechanism, 
less land space. Two types of VAWTs are mainly used, namely savonius and darrieus wind turbine rotors. The darrieus wind rotor is a simple and cheapest wind turbine, and at low wind speed, it can produce power over the savonius wind turbine [5-7].

At present, the authors are concentrated on the VAWT. In particular, this paper has been focused on a special type of VAWT with straight blades, also referred to as straight-bladed darrieus rotor or as $\mathrm{H}$ rotor, the $\mathrm{H}$ representing its cross-vertical section. The energy industry currently attends on ways to improve wind turbine performance to minimize losses of the wind turbine. Internal losses by the vibration in operating conditions are one of the reasons for reducing the efficiency of wind turbine power generation. In addition, vibration occurs at a low frequency $(\leq 10 \mathrm{~Hz})$ [8]. Reducing vibrations are one of the solutions to minimize the maintenance cost of the wind turbine as well as higher power production. Therefore, significant consideration has been given by researchers to study the vibrations in a wind turbine. In studying the vibration behavior of wind turbines, many approaches have been used. These different approaches are made experimentally, modeling or simulation. McLaren et al. [9] pointed out the existence of significant vibration three times the frequency of rotation, which is caused by aerodynamic loading on the three-bladed, three meters long of VAWT. Li [10] investigated the relationship between vibration parameters and the design of a simple VAWT. Using SolidWorks, a simple model of the turbine was developed with three blades and analyzed through finite element analysis (FEA).

The aerodynamic performance of VAWTs has achieved rich literature based on computational fluid dynamics (CFD) and blade element momentum (BED) theory. Mohamed et al. [11] studied the numerical analysis of Darrius wind turbine at low wind speed using CFD with various airfoils and introduced a new shape of wind turbine blades. The computational method achieves considerable improvements in the understanding of the VAWT thanks to its inherent flexibility for analyzing complex unsteady flow around wind turbines. The CFD codes can also surmount the limitations in low Reynolds number by the integration of the Navies Stokes equations around the blade profile. The most important advantage of the CFD analysis is its ability to simulate the configurations at the wind tunnel test conditions and to generate results that are compared favorably with experimental data [12]. In this context, Castelli et al. [13] perform a numerical simulation validation for a darrieus wind turbine by systematic comparison with wind tunnel experimental data.

As wind turbine towers are being placed in varying global wind environments, knowledge of the dynamic behavior of the sub-components of the system, mainly the tower and rotor blades, as well as the dynamic interactions of those components with each other, is vital to ensure the serviceably and survivability of such expensive infrastructure [14]. One way of reducing the operating cost is by minimizing turbine vibration. Minimal turbine vibration results in an extended life cycle of the wind turbine's components. Adaptability to the rapidly varying environmental factor is also essential for a wind turbine. In harsh conditions, cyclic loading of the structure due to rotation of blades could compromise the safe operation of the wind turbine if critical levels are exceeded. Therefore, understanding the dynamic behavior of the wind turbine would be a great prospect for future development in designing a better wind turbine. In this experiment, a VAWT will be used since there is not much research regarding vibration done in this fairly new type of wind turbine. VAWT power has been produced by different wind speeds such as normal flow and controller flow. The flow conditioner tested did have a big impact on the response of the structure in terms of vibration up to $30 \%$ indifference, but not so much in power generated about $2 \%$ indifference.

Therefore, this study was initiated to implement and performance of a VAWT under uniformed speed. The novelty of this study lies in the performance analysis of VAWT power during vibration, which effected by uniformed speed. This study is structured as follows: 
- A VAWT has been implemented for experimental execution under conditioned and normal speed. (Section 2).

- To evaluate the performance of the experimental study of VAWT turbine vibration under uniformity speed has been conducted. (Section 3).

Experimental results have been analyzed to demonstrate the effect of vibration of the wind turbine. (Section 4).

\section{Vertical Axis Wind Turbine}

The main rotor shaft of a VAWT is in a vertical manner with the rest of the components at its base or on the ground. Several advantages of this set-up most notably are ease of maintenance with the gearboxes and generators at the ground and the fact that it does not need to be in the direction of the wind. Different types of VAWT have been explained in this section Savonius wind turbines are a type of VAWT used for converting the force of the wind into torque driving the shaft [15]. Savonius consist of scopes which makes it a drag-type device. A two-scoop Savonius would resemble an "S" shape when observing from the top. Due to its design, scoops undergo less drag when moving against them when moving with the wind. Different in drag results in the turbine spinning. Savonius extracts much less wind power than other types.

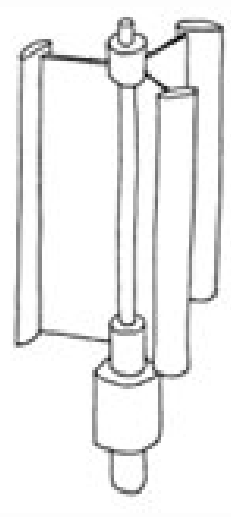

(a)

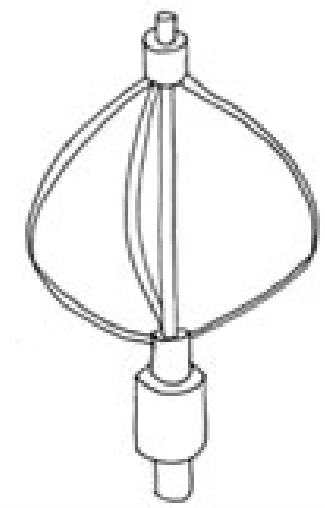

(b)

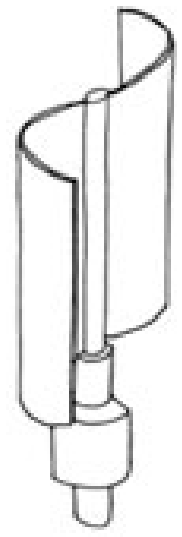

(c)

Fig. 1. (a) Giromill wind turbine [16]; (b) Darrieus wind turbine [16];

(c) Savonius wind turbine [16].

An example of a Savonius wind turbine is shown in Fig. 1(c) [17]. Darrieus wind turbine Fig. 1 (b) is a type of VAWT that generates electricity from the energy possesses by the wind. Darrieus consists of a number of curved airfoil blades attached to the main vertical shaft. Darrieus wind turbines are difficult to protect against extreme wind conditions and in making it self-starting [18]. A problem with the design is that the angle of attack changes as the turbine spins, so each blade generates maximum torque at two points on its front and back in a cycle [19]. Giromill wind turbine is similar to Darrieus, in which the "egg-beater" blades of Darrieus design are replaced with straight vertical blade sections attached to the central shaft [20]. The operation way of a Giromill wind turbine is not different from that of a common Darrieus turbine. The wind hits the blades, and velocity is split into lift and drag components. The resultant vector sum of these two components of the velocity makes the turbine rotate. This paper will be concentrating on a similar structure of a Giromill type of wind turbine, but with a higher number of blades rather than two in the Giromill wind turbine [20]. An example of a Giromill wind turbine is shown in Fig. 1(a). Eq. (1) is indicated the power $P$ of the Vertical axis wind turbine [21,22]. 


$$
P=\frac{1}{2} C_{p} \rho A v^{3}
$$

where $C_{p}$ is the power coefficient, $\rho$ is the air density, $A$ is the swept area of the rotor blade, and $v$ is the wind velocity. The tip speed $\lambda$ shows the relation between wind speed and rotational speed of rotor $\omega$. The tip speed is represented as [23]

$$
\lambda=\frac{\omega R}{v}
$$

where $\mathrm{R}$ is the radius of wind turbines and $\omega$ is the rotational speed of the turbine. Therefore, significant consideration has been given by researchers to study the vibrations in a wind turbine. In studying the vibration behavior of wind turbines, many approaches have been used. These different approaches are made experimentally, modeling or simulation. The wind turbine is the main component of this experimental study. A small vertical axis wind turbine of model number SAV-45W acquired from Saiam Power was used for this experiment, shown in Table 1. It is self-starting in low wind conditions and able to capture wind from any direction with minimal height and floor space setup requirement. The wind turbine consists of five blades, each blade with a length of $0.525 \mathrm{~m}$, made of aluminium alloy supported by the erosionresistant aluminium structure and equipped with a three-phase alternating current (AC) permanent magnet, gearless turbine motor. Fully assembled, the rotor diameter would be 0.56 $\mathrm{m}$ with a swept area of $0.3 \mathrm{~m}^{2}$. The structure of the VAWT tower was fabricated using steel with flanges at both ends, as shown in Fig. 2(a). The tower itself is $1 \mathrm{~m}$ in height from flanges, endto-end, hollow in the middle with a larger diameter of $0.03 \mathrm{~m}$ and a thickness of $3 \mathrm{~mm}$. The top part of the tower connected to the turbine has a flange with an outer diameter of $0.09 \mathrm{~m}$ and inner diameter of $0.036 \mathrm{~m}$, including five holes each $9 \mathrm{~mm}$ in diameter to allow fastening to the turbine structure using bolts and nuts. The base flange is $0.12 \mathrm{~m}$ in outer diameter and $0.036 \mathrm{~m}$ inner diameter. The base flange has seven holes on the same $9 \mathrm{~mm}$ diameter for fastening to the base. A simple model to represent to tower structure of the turbine was constructed in the software. A total of 6 points is marked on the model. Basically, point 1 in the model is located close to the turbine at the top of the tower structure and point 6 bottoms of the tower and equal distance in between point 1 to 6 . A graphical representation of the model is shown in Fig. 2(b).

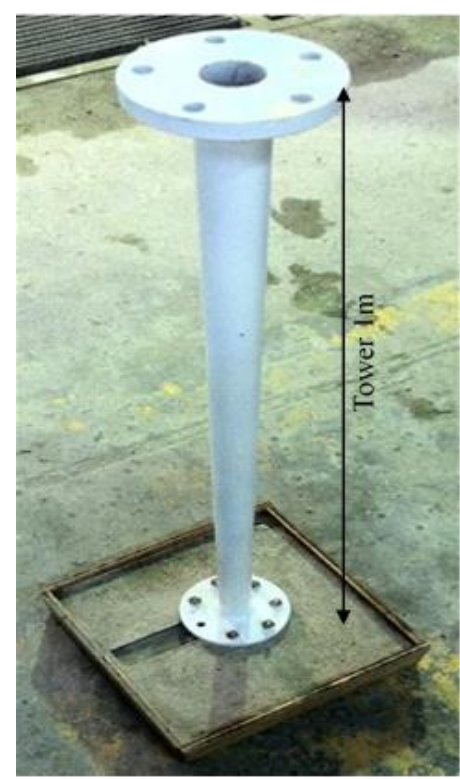

(a)

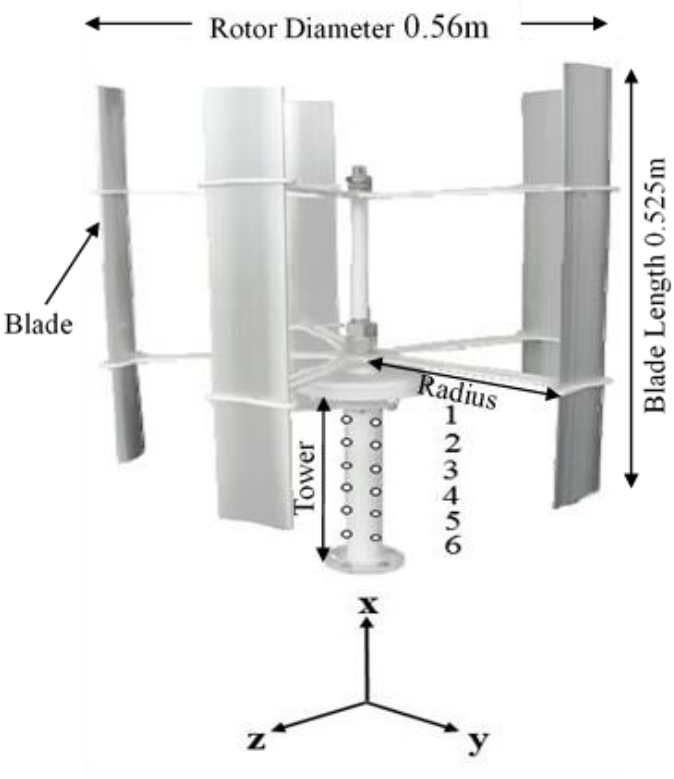

(b)

Fig. 2. (a) Tower structure attached to a concrete base; (b) Graphical representation of the tower structure 
Table 1. SAV-45W VAWT Model

\begin{tabular}{cc}
\hline Performance & Value \\
\hline Rated power & $30 \mathrm{~W}$ \\
\hline Peak power & $45 \mathrm{~W}$ \\
\hline Cut-in wind speed & $2 \mathrm{~ms}^{-1}$ \\
\hline Rated wind speed & 3 to $20 \mathrm{~ms}^{-1}$ \\
\hline Cut-out wind speed & $35 \mathrm{~ms}^{-1}$ \\
\hline Rotor diameter & $0.56 \mathrm{~m}$ \\
\hline Swept area & $0.3 \mathrm{~m}^{2}$ \\
\hline Blade & $5 \mathrm{pcs}$ aluminium alloy \\
\hline Blade Length & $0.525 \mathrm{~m}$ \\
\hline Rotor Speed & $300 \mathrm{rpm}$ \\
\hline
\end{tabular}

\section{Experimental Set-up}

In this experimental setup, various components have been used for the conducting experiment. For EMA, the impact hammer was connected to the first channel on the DAQ hardware while the triaxial accelerometer was connected to the other three channels with the $\mathrm{X}$-axis cable connected to the second channel followed by $\mathrm{Y}$ axis and $\mathrm{Z}$ axis in the third and fourth channel, respectively, as shown in Fig. 3(a). DAQ hardware mounted on its carrier was connected to the computer through a universal serial bus (USB) port. The computer is installed with DASYLab Version 10.0 and ME'ScopeVES software to analyze collected results.

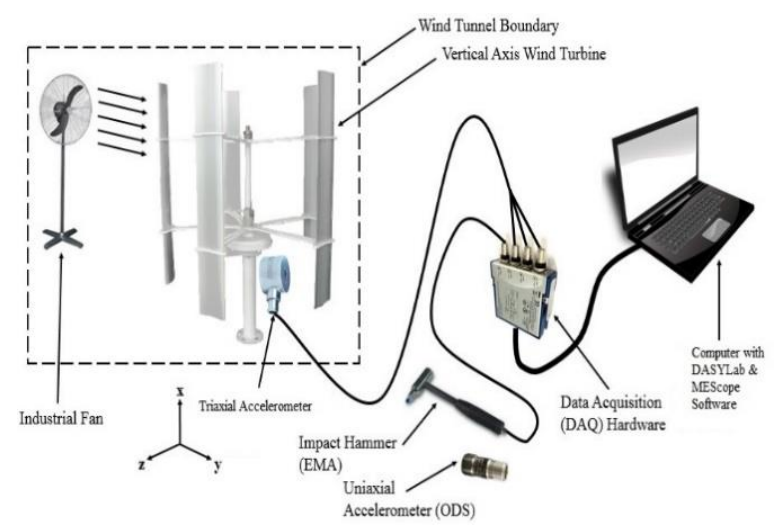

(a)

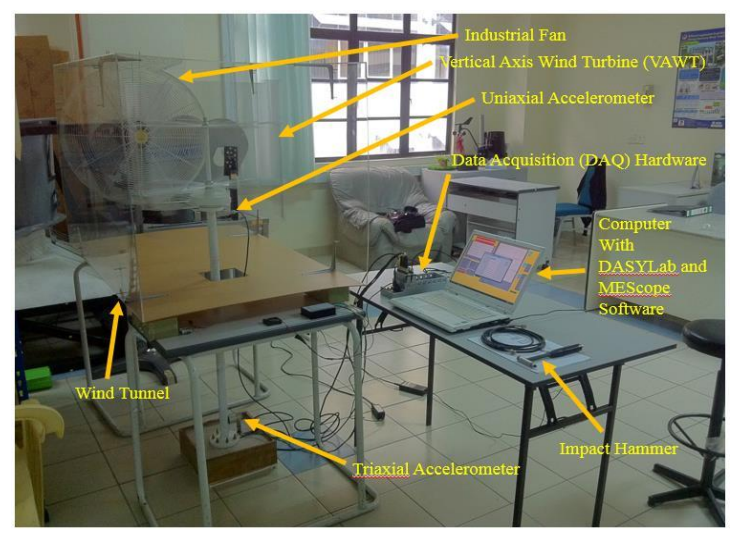

(b)

Fig. 3. (a) Schematics of experimental set-up; (b) Experimental set-up on operation

In testing the VAWT, an open-loop wind tunnel was fabricated of acrylic plastic sheets, which are assembled using bolts and nuts shown in Fig. 3(b). The square cross-section of the tunnel was $0.8 \mathrm{~m} \times 0.8 \mathrm{~m}$, and the length of the tunnel was $1.25 \mathrm{~m}$. The wind was generated by a single two-bladed industrial fan model FS/FB-65. The fan, 26 " in diameter, can operate at variable speeds with a maximum blade rotation of $1350 \mathrm{rpm}$. The wind turbine is placed in the middle, $0.4 \mathrm{~m}$ from the sides and $0.85 \mathrm{~m}$ downstream of the tunnel because of obtaining the stable wind speed from the industrial fan. The VAWT was placed inside the wind tunnel, with the industrial fan placed at the inlet of the tunnel. For ODS measurement, the set-up differences are that the first channel of the DAQ hardware was replaced with the uniaxial accelerometer, and instead of fixing the triaxial accelerometer, the uniaxial was fixed at the same point. It was generated by a single two-bladed industrial fan model FS/FB-65. The fan, 26" in diameter, can operate at variable speeds with a maximum blade rotation of 1350 RPM. 


\section{Results and Discussion}

\subsection{Effect on Vibration}

The turbine tower structure is fixed to the ground. The structure is basically a cantilever beam in a vertical direction with the addition of the turbine components at the top of the structure. Therefore, it is expected that the maximum response that can be produced would be at the top of the structure. Therefore, the nearest point to the top is point 1. In this part of the analysis, point 1 of the structure would be the reference point and basis of vibration comparison in two axes, $\mathrm{Y}$ and $\mathrm{Z}$ are shown in Table 2 and Table 3, respectively. These two axes are major contributors in terms of the structure's response. To further ease the analysis, displacement FRF would be used. Displacement directly gives the amount that the structure is displaced due to the response in operating conditions.

Table 2. Displacement response at point 1 in Y direction

\begin{tabular}{cccccc}
\hline Point & $\begin{array}{c}\text { Fan } \\
\text { Speed(rpm) }\end{array}$ & Flow & $\begin{array}{c}\text { Frequency } \\
(\mathbf{H z})\end{array}$ & $\begin{array}{c}\text { Displacement } \\
(\boldsymbol{\mu} \mathbf{m})\end{array}$ & $\begin{array}{c}\text { Displacement Percentage (\%) } \\
\text { Difference }\end{array}$ \\
\hline 1 & 1150 & Normal & 1.58 & 44.242 & 26.74 \\
\hline 1 & 1150 & Conditioned & 1.50 & 32.411 & \multirow{2}{*}{31.48} \\
\hline 1 & 1250 & Normal & 2.30 & 61.644 & \multirow{2}{*}{35.26} \\
\hline 1 & 1250 & Conditioned & 2.20 & 42.239 & \\
\hline 1 & 1350 & Normal & 2.60 & 93.790 & \\
\hline
\end{tabular}

Table 3. Displacement response at point 1 in $\mathrm{Z}$ direction

\begin{tabular}{cccccc}
\hline Point & $\begin{array}{c}\text { Fan Speed } \\
(\mathbf{r p m})\end{array}$ & Flow & $\begin{array}{c}\text { Frequency } \\
(\mathbf{H z})\end{array}$ & $\begin{array}{c}\text { Displacement } \\
(\boldsymbol{\mu} \mathbf{m})\end{array}$ & $\begin{array}{c}\text { Displacement Percentage }(\%) \\
\text { Difference }\end{array}$ \\
\hline 1 & 1150 & Normal & 1.58 & 59.061 & \multirow{2}{*}{67.74} \\
\hline 1 & 1150 & Conditioned & 1.50 & 19.054 & \multirow{2}{*}{7.96} \\
\hline 1 & 1250 & Normal & 2.30 & 42.239 & \multirow{2}{*}{24.62} \\
\hline 1 & 1250 & Conditioned & 2.20 & 38.877 & \\
\hline 1 & 1350 & Normal & 2.60 & 72.565 & \\
\hline
\end{tabular}

Based on the results obtained and analyzed in Y-axis at point 1, as shown in Table 2, the highest displacement percentage difference is about 35.26 percent at speed 1350 for both normal and condition flow. On the other hand, the lowest displacement difference is about 26.74 percent at speed 1150. In addition, the frequency of the Y-axis of each point is almost the same for normal and conditioned flow.

From the results obtained in Z-axis at point 1 is shown in Table 3, the lowest displacement difference percentage is 7.96 at speed 1250 for both normal and conditional flow of wind. Wind turbine output power is not affected by the lower displacement percentage, and the displacement percentage is the highest in Z-axis at speed 1150. The highest value of 67.74 is countable for output power reduction. In comparison, the percentage difference is the lowest at fan speed 1250. The frequency of the Z-axis of each point is almost the same for normal and conditioned flow. The excitation frequency exerted on the turbine slightly drops compared to the unconditioned or the normal flow of air. However, the difference is very small, so it is assumed to be negligible, and the turbine is considered to operate at the same excitation frequency for each speed.

Therefore, the basis of comparison in terms of vibration is whether the installation of the flow conditioner does affect the response of the structure. Based on the result, in each case, the amount of response or displacement is compared between the normal flow and the conditioned flow. The results show that amount of displacement for which the flow conditioner installed is lower than the displacement recorded for the normal or unconditioned flow of air. Percentage 
difference was calculated for the same operating speeds but with different flow conditions in the same deflection axis. The smallest percentage difference calculated was $7.96 \%$, while the largest was $67.74 \%$. The average percentage difference for all the cases was found to be $32.3 \%$.

\subsection{Effect on Power Generation}

Apart from the vibration analyst who is through the displacement FRF from the ODS, the effects of the flow conditioner on the power generated by the turbine in variable operating speeds are also analyzed. The power generated is the most important aspect of the VAWT, and the sole purpose of its construction is to generate power through the wind as a source of renewable energy. Power generated was measured in a conventional way by using a multimeter. The turbine was allowed to reach the constant number of rotations whereby measurement of the power generated is taken only after it has reached that steady operating condition. The results of the measurement are shown in Table 4.

Table 4. The effect of speed and flow condition of power generated.

\begin{tabular}{ccccc}
\hline $\begin{array}{c}\text { Speed } \\
(\mathbf{r p m})\end{array}$ & Flow & $\begin{array}{c}\text { Frequency } \\
(\mathbf{H z})\end{array}$ & $\begin{array}{c}\text { Voltage Generated } \\
(\mathbf{V})\end{array}$ & $\begin{array}{c}\text { Percentage (\%) Difference of Power } \\
\text { Generation }\end{array}$ \\
\cline { 1 - 4 } 1150 & Normal & 1.58 & 5.81 & \multirow{2}{*}{2.41} \\
\hline 1150 & Conditioned & 1.50 & 5.67 & \multirow{2}{*}{2.49} \\
\hline 1250 & Normal & 2.30 & 8.82 & \multirow{2}{*}{2.03} \\
\hline 1250 & Conditioned & 2.20 & 9.04 & \\
\hline 1350 & Normal & 2.60 & 10.82 & \\
\hline 1350 & Conditioned & 2.50 & 11.04 & \\
\hline
\end{tabular}

From the results, power generation increases with the turbine's rotational speed. At speeds 1150, the power difference of normal and conditional flow is about 2.41 percent. At speed 1250, the conditional voltage is increased with $2.20 \mathrm{~Hz}$ frequency. Whereas, at normal flow, the voltage decreases with $2.30 \mathrm{~Hz}$ frequency, and finally, the power generation percentage is slightly an increase over speeds 1150 . The difference in power generation percentage is very low at speed 1350. The effect of speed in the turbine is not significant. The effects of the flow conditions on the power generation are minimal for each different operating turbine speed. Power generation calculated shows that for each case of approximately $2 \%$ difference with different flow conditions.

\section{Conclusion}

One of the objectives of this experimental study is to set up an experiment to identify the dynamic characteristics of a VAWT tower structure. By applying the EMA and ODS techniques, the results of both parts are correlated. EMA determines the dynamic characteristics - the natural frequencies, mode shapes, and the amount of damping in the structure, while ODS gives the behavior of structure while in operating condition. EMA identifies 7 modes in the Y-axis direction, while in the Z-axis direction, 5 modes are identified. Excitation frequencies imposed onto the structure by varying the speeds of the industrial fan to imitate wind conditions in operation during ODS were found to be far from the first natural frequencies in either Y or Zaxis direction.

Therefore, it can be concluded that the turbine structure is safe for operation within the tested range of excitation frequencies as it will not undergo any resonance conditions in these ranges. Another objective of this experimental study is to compare the effects of different speeds and airflow on tower structure vibration and power generation. An experiment was conducted to test different cases of speeds and varied for the next part with the addition of the flow conditioner. From the results, the magnitude of displacement, which is the reference for vibration in this study, was found to increase with the increase of speeds, whether it is in the $Y$ or Z-axis direction without the flow conditioner. Vibration still increases with the increase in 
the airflow speed, but in comparing the normal and conditioned flow of the same speed, a displacement difference of $32.3 \%$ on average. The addition of a flow conditioner greatly reduces the tower structure vibrations through this study. From the results, power generation increases with the increase in the turbine's rotational speed of both conditioned normal and conditioned airflow. By comparing the effects of the flow conditioner, however, for the same speeds, percentage differences calculated for all the cases obtain the average of only $2.31 \%$ power generation difference. The effect of the conditioned flow on power generation is minimal.

\section{Acknowledgment}

The authors would like to express their gratitude to the Minister of Higher Education of Malaysia and University Malaya (ER0142013A and RP015C-13AET) for funding and providing facilities to conduct the research.

\section{References}

[1] F. Scheurich, T. M. Fletcher, and R. E. Brown, "Simulating the aerodynamic performance and wake dynamics of a vertical-axis wind turbine," Wind Energy, vol. 14, no. 2, pp. 159-177, 2011. https://doi.org/10.1002/we.409

[2] R. Sarkar, S. Julai, S. Hossain, W. T. Chong, and M. Rahman, "A comparative study of activation functions of NAR and NARX neural network for long-term wind speed forecasting in Malaysia," vol. 2019, 2019. https://doi.org/10.1155/2019/6403081

[3] I. B. Mabrouk, A. El Hami, L. Walha, B. Zghal, and M. Haddar, "Dynamic vibrations in wind energy systems: Application to vertical axis wind turbine," Mechanical Systems and Signal Processing, vol. 85, pp. 396-414, 2017. https://doi.org/10.1016/j.ymssp.2016.08.034

[4] M. Sarkar, S. Julai, C. Wen Tong, and S. F. Toha, "Effectiveness of Nature-Inspired Algorithms using ANFIS for Blade Design Optimization and Wind Turbine Efficiency," vol. 11, no. 4, p. 456, 2019. https://doi.org/10.3390/sym11040456

[5] S. Li et al., "Experimental investigation of solidity and other characteristics on dual vertical axis wind turbines in an urban environment," vol. 229, p. 113689, 2021. https://doi.org/10.1016/j.enconman.2020.113689

[6] J. T. Hansen, M. Mahak, and I. J. R. E. Tzanakis, "Numerical modelling and optimization of vertical axis wind turbine pairs: A scale up approach," vol. 171, pp. 1371-1381, 2021. https://doi.org/10.1016/j.renene.2021.03.001

[7] B. Hand and A. Cashman, "A review on the historical development of the lift-type vertical axis wind turbine: From onshore to offshore floating application," vol. 38, p. 100646, 2020. https://doi.org/10.1016/j.seta.2020.100646

[8] E. Mollasalehi, Q. Sun, and D. Wood, "Contribution of Small Wind Turbine Structural Vibration to Noise Emission," Energies, vol. 6, no. 8, pp. 3669-3691, 2013. https://doi.org/10.3390/en6083669

[9] K. McLaren, S. Tullis, and S. Ziada, "CFD simulation of dynamic thrust and radial forces on a vertical axis wind turbine blade," in The 15th Annual Conference of the CFD Society of Canada, Toronto, 2007.

[10] L. Li, "Vibrations analysis of vertical axis wind turbine: a thesis presented in partial fulfilment of the requirements for the degree of Master of Engineering in Mechatronics, School of Engineering and Advanced Technology, Massey University, New Zealand," Massey University, 2012.

[11] M. Mohamed, A. Ali, and A. Hafiz, "CFD analysis for H-rotor Darrieus turbine as a low speed wind energy converter," Engineering Science and Technology, an International Journal, vol. 18, no. 1, pp. 1-13, 2015. https://doi.org/10.1016/j.jestch.2014.08.002

[12] M. D. Patel and T. P. Gundarneeya, "Performance Analysis of Vertical Axis Wind Turbine with Comparison of CFD and Experimental Analysis," International Journal For Science Technology And Engineering, vol. 1, no. 5, pp. 36-44, 2014.

[13] M. R. Castelli, G. Ardizzon, L. Battisti, E. Benini, and G. Pavesi, "Modeling strategy and numerical validation for a Darrieus vertical axis micro-wind turbine," in ASME 2010 International Mechanical 
Engineering Congress and Exposition, 2010, pp. 409-418, American Society of Mechanical Engineers. https://doi.org/10.1115/IMECE2010-39548

[14] M. R. Sarkar, S. Julai, C. W. Tong, M. Uddin, M. Romlie, and GM. Shafiullah, "Hybrid pitch angle controller approaches for stable wind turbine power under variable wind speed," vol. 13, no. 14, p. 3622, 2020. https://doi.org/10.3390/en13143622

[15] J.-H. Lee, Y.-T. Lee, and H.-C. Lim, "Effect of twist angle on the performance of Savonius wind turbine," Renewable Energy, vol. 89, pp. 231-244, 2016. https://doi.org/10.1016/j.renene.2015.12.012

[16] W. Tjiu, T. Marnoto, S. Mat, M. H. Ruslan, and K. Sopian, "Darrieus vertical axis wind turbine for power generation II: Challenges in HAWT and the opportunity of multi-megawatt Darrieus VAWT development," Renewable Energy, vol. 75, pp. 560-571, 2015. https://doi.org/10.1016/j.renene.2014.10.039

[17] S. Roy and A. Ducoin, "Unsteady analysis on the instantaneous forces and moment arms acting on a novel Savonius-style wind turbine," Energy Conversion and Management, vol. 121, pp. 281-296, 2016. https://doi.org/10.1016/j.enconman.2016.05.044

[18] M. T. Asr, R. Osloob, and F. Mustapha, "Double-stage H-Darrieus Wind Turbine-Rotor Aerodynamics," Applied Mechanics \& Materials, vol. 829, 2016. https://doi.org/10.4028/www.scientific.net/AMM.829.21

[19] M. Zamani, M. J. Maghrebi, and S. R. Varedi, "Starting torque improvement using J-shaped straightbladed Darrieus vertical axis wind turbine by means of numerical simulation," Renewable Energy, vol. 95, pp. 109-126, 2016. https://doi.org/10.1016/j.renene.2016.03.069

[20] M. El-Samanoudy, A. Ghorab, and S. Z. Youssef, "Effect of some design parameters on the performance of a Giromill vertical axis wind turbine," Ain Shams Engineering Journal, vol. 1, no. 1, pp. 85-95, 2010. https://doi.org/10.1016/j.asej.2010.09.012

[21] J. F. Manwell, J. G. McGowan, and A. L. Rogers, Wind energy explained: theory, design and application. John Wiley \& Sons, 2010. https://doi.org/10.1002/9781119994367

[22] M. R. Sarkar, M. J. Nahar, A. Nadia, M. A. Halim, S. S. H. Rafin, and M. M. Rahman, "Proficiency Assessment of Adaptive Neuro-Fuzzy Inference System to Predict Wind Power: A Case Study of Malaysia," in 2019 1st International Conference on Advances in Science, Engineering and Robotics Technology (ICASERT), 2019, pp. 1-5: IEEE. https://doi.org/10.1109/ICASERT.2019.8934557

[23] C.-J. Bai, P.-W. Chen, and W.-C. Wang, "Aerodynamic design and analysis of a $10 \mathrm{~kW}$ horizontalaxis wind turbine for Tainan, Taiwan," Clean Technologies and Environmental Policy, vol. 18, no. 4, pp. 1151-1166, 2016. https://doi.org/10.1007/s10098-016-1109-z 